\title{
Adhesion molecule expression on epithelial cells infected with respiratory syncytial virus
}

\author{
S-Z. Wang*, P.G. Hallsworth**, K.D. Dowling***, J.H. Alpers ${ }^{+}$, J.J. Bowden ${ }^{+}$, K.D. Forsyth*
}

\begin{abstract}
Adhesion molecule expression on epithelial cells infected with respiratory syncytial virus. S-Z. Wang, P.G. Hallsworth, K.D. Dowling, J.H. Alpers, J.J. Bowden, K.D. Forsyth. (C) ERS Journals Ltd 2000

ABSTRACT: Respiratory epithelium is both a target and an effector of airway inflammation. Adhesion molecules on epithelium play an important role in a variety of airway diseases. Respiratory syncytial virus (RSV) is the most important pathogen for airway diseases in infants. The expression of adhesion molecules on epithelium in RSV infection, however, is unclear.

The expression of selected adhesion molecules and major histocompatibility complex (MHC) class I and II antigens on a human alveolar type II epithelial cell line (A549) infected with RSV was investigated by means of flow cytometry and immunocytochemistry.

The results showed that intercellular adhesion molecule-1 (ICAM-1) and vascular cell adhesion molecule-1 (VCAM-1) were expressed on A549 cells at a low level. Ecadherin and MHC class I antigen were constitutively expressed on the cells. RSV infection of A549 cells significantly upregulated the expression of ICAM-1, VCAM-1 and MHC class $I$ and II antigens on these cells. RSV infection also altered the expression of E-cadherin on A549 cells. Immunostaining showed that E-cadherin was mainly upregulated around or in RSV-induced giant cells.

These data suggest that respiratory syncytial virus infection of respiratory epithelial cells enhances the expression of adhesion molecules and major histocompatiblity complex antigens. These changes may play an important role in the pathophysiology of respiratory syncytial virus disease.

Eur Respir J 2000; 15: 358-366.
\end{abstract}

Depts of *Paediatrics **Microbiology ***Pathology, and ${ }^{+}$Respiratory Medicine, Flinders Medical Centre, Flinders University, Adelaide, South Australia, Australia.

Correspondence: K.D. Forsyth, Dept of Paediatrics, Flinders Medical Centre, Flinders University, Bedford Park, South Australia 5042, Australia. Fax: 61882045593

Keywords: Adhesion molecule epithelial cell

infection

respiratory syncytial virus

Received: April 271999

Accepted after revision October 251999

S.Z. Wang was supported by an Australian Overseas Postgraduate Research Scholarship (OPRS) and Flinders University University Research Budget. This research was, in part, supported by the Channel Seven Children's Research Foundation of South Australia, Inc. (Grant No. 30, 1997/ 1998) and the Gunn Medical Research Foundation (1997/1998).
The respiratory epithelium is not only a physical barrier between environmental noxious agents and the internal body milieu but also a metabolically active physiochemical structure [1]. Respiratory epithelial cells are both "target" and "effector" cells in airway inflammation [2]. As target cells, epithelial cells can be infected and damaged by various pathogens, such as respiratory syncytial virus (RSV) [3]. As effector cells, epithelial cells can express adhesion molecules, such as intercellular adhesion molecule-1 (ICAM-1) [4-6], and can produce a wide array of cytokines $[2,7]$, and thereby be involved in inflammation and immune responses.

RSV is the most frequent cause of bronchiolitis and pneumonia in infants requiring hospitalization [8]. Moreover, $\geq 50 \%$ of infants who have acute viral bronchiolitis due to RSV have subsequent episodes of wheezing consistent with asthma [9] and it seems that there is a strong link between RSV bronchiolitis and asthma in epidemiology and immunology, reviewed by WANG and ForSYTH [10]. It has previously been reported that RSV infection can damage epithelial cells to a certain extent and neutrophils can augment the epithelial damage and detachment induced by RSV [3]. However, the pathophysiology of RSV disease, especially the role of respiratory epithelial cells in RSV infection, is unclear. Although the cytokine production profile of respiratory epithelial cells in RSV infection has been well studied [7, 11-14], the expression of adhesion molecules on epithelial cells in RSV infection is poorly understood $[3,5]$.

It has been demonstrated that both primary cultured bronchial epithelial cells and the cultured epithelial cell line BEAS-2B, constitutively express ICAM-1 and leukocyte function-associated molecule-3, but only ICAM-1, expressed on both cell types can be upregulated after stimulation [15]. Besides ICAM-1, human bronchial epithelial cells constitutively express major histocompatibility complex (MHC) class I antigen and other molecules [16]. Culture of BEAS-2B cells with tumour necrosis factor- $\beta$ (TNF- $\alpha$ ) and interleukin (IL)-1 $\beta$ was found to enhance ICAM-1 and induce de novo vascular cell adhesion molecule-1 (VCAM-1, CD106) expression [16].

Although it has been reported that RSV infection upregulates ICAM-1 expression on epithelial cells and ICAM-1 is the only known ligand on epithelial cells for neutrophil binding to A549 cells [5], it is unclear whether RSV infection could induce the upregulation of ICAM-1 on A549 cells in a dose- and time-dependent pattern. Moreover, VCAM-1 is a recently reported adhesion molecule expressed on airway epithelial cells [16], and the effect of RSV infection on VCAM-1 expression is unknown. 
E-cadherin is heavily distributed on the basolateral domain of alveolar type II cells [17] and mediates epithelial cell/cell adhesion. However, there is no report of the expression of E-cadherin on respiratory epithelial cells in RSV infection. The authors speculate that RSV infection may upregulate the expression of E-cadherin on A549 cells. Such upregulation may be involved in the formation of giant cells in RSV infection.

As epithelial cells are likely to be "nonprofessional" antigen-presenting cells (APCs) [5, 18], the expression of MHC class I and II antigens on A549 cells in RSV infection is also of interest.

It was hypothesized that RSV infection may upregulate the expression of adhesion molecules on epithelial cells, which may contribute to the pathophysiology of RSV disease. Therefore, the aim of this study was to investigate the expression of adhesion molecules on respiratory epithelial (A549) cells infected with RSV. In addition to ICAM-1, VCAM-1, and E-cadherin, the expression of MHC class I and II antigens on A549 cells in RSV infection were also investigated.

\section{Materials and methods}

\section{Epithelial cell culture}

A549, an immortalized human alveolar type II epithelial cell line (American Type Culture Collection (ATCC), Rockville, MD, USA), was selected as the source of respiratory epithelial cells for these studies [5, 19], because of its standardized use as a respiratory epithelial cell line, and its low baseline expression of ICAM-1. A549 cells were cultured in Dulbecco's modified Eagle's medium (DMEM) plus $5 \%$ foetal calf serum (FCS). Each well $\left(9.62 \mathrm{~cm}^{2}\right)$ of a six-well plate (Becton Dickinson Labware, Franklin Lakes, NJ, USA) was seeded with $0.75 \times 10^{6}$ cells and each chamber $\left(1 \mathrm{~cm}^{2}\right)$ of an eight-chamber plate (Nunc Inc., Naperville, IL, USA) was seeded with $0.75 \times 10^{5}$ cells. After 24-36 h of culture in an atmosphere of 5\% in a humidified incubator $\mathrm{CO}_{2} /$ air $37^{\circ} \mathrm{C}$, the cells in the wells or chambers formed confluent monolayers, $1.5 \times 10^{6}$ cells. well $^{-1}$ and $1.5 \times 10^{5}$ cells $\cdot$ chamber $^{-1}$, respectively.

\section{Study design}

Two methodologies were utilized at the same time: flow cytometric analysis to quantify the intensity of expression of adhesion molecules; and immunocytostaining to visualize the expression of adhesion molecules on A549 cells [20]. Different doses of RSV (at multiplicities of infection (MOIs) of 0.01, 0.1 and 1.0) were used in the infection of epithelial cells in six-well plates for flow cytometric analysis. RSV at a MOI of 1.0 was used to infect the cells in eight-chamber slides for immunocytostaining. The effect of RSV was investigated at 6, 24 and $48 \mathrm{~h}$ of infection. Sterile culture medium was used as a negative control. Inactivated RSV (RSVi) was not employed as a control, as a previous study had shown that active RSV had a significantly stronger effect than RSVi on leukocyte/epithelial adhesion [3].

\section{Antibodies}

The following monoclonal antibodies (mAbs) were used in this study: anti-ICAM-1 (Clone 84H10 (IgG1); Imm- unotech, Marseille, France), anti-VCAM-1 (Clone 1G11 (IgG1); Immunotech), anti-E-cadherin (Clone 67A4 (IgG1); Immunotech), anti-MHC class I antigen (Clone FMC16, (IgG2a/k); Flinders Medical Center, Adelaide, Australia), anti-MHC class II antigen (Clone FMC52 (IgG1/k); Flinders Medical Center), and negative control (Clone X63 (IgG1); ATCC). The dilutions of mAbs used for immunocytostaining were: anti-ICAM-1, 1:50; anti-VCAM-1, 1:50; anti-E-cadherin 1:50; anti-MHC class I antigen, 1:10 of supernatant; and anti-MHC class II antigen, 1:10 of supernatant.

\section{Virus preparation}

The characterized long strain of RSV (88:RS4) was originally obtained from P. Young of the Sir Albert Sakzewski Virus Research Center, Royal Children's Hospital, Brisbane, Australia. The virus was propagated from a frozen stock by inoculating fresh HEp-2, an immortalized human laryngeal epithelial tumour cell line (ATCC, Rockville, MD), cells with the virus and incubating them for 3 days; the virus-infected cells were then harvested, sonicated and stored in aliquots in liquid nitrogen. The titre was determined by means of the median tissue culture infective dose (TCID50) [21] and fluorescent focus assays. The two assays have been shown to correlate well in determining RSV titre. However, the fluorescent focus assay is much quicker to perform than the TCID50 assay and is more commonly used. Briefly, cultures of Hep-2 cells were inoculated with dilutions of the virus, incubated in $5 \%$ $\mathrm{CO}_{2}$ for $18 \mathrm{~h}$ at $37^{\circ} \mathrm{C}$, and then stained with fluorescein isothiocyanate (FITC)-labelled anti-RSV (Bartels, Issaquah, WA, USA). The fluorescing cells were counted and the virus titre was calculated assuming each fluorescent focus represented 1 infectious unit of virus. Typically virus preparations contained $1 \times 10^{7}-6 \times 10^{7}$ fluorescent focus-forming units of RSV $\cdot \mathrm{mL}^{-1}$. Crude RSV extracts were used in these experiments in keeping with previously published data.

\section{Viral infection of epithelial cells}

Different doses of RSV (MOIs of 0.01, 0.1 and 1.0) were used in the infection of epithelial cells [3]. RSV diluted in DMEM plus 2\% FCS were added to the confluent A549 monolayers in each well or chamber and incubated in humidified $5 \% \mathrm{CO}_{2} /$ air for $2 \mathrm{~h}$ at $37^{\circ} \mathrm{C}$ (to allow virus adsorption). The supernatant was removed and all wells or chambers were washed once with DMEM. DMEM plus $2 \%$ FCS, 5 or $0.5 \mathrm{~mL}$, was added to each well or chamber respectively and cultured to specific time points $(6,24$, and $48 \mathrm{~h}$ ) in the incubator.

\section{Flow cytometric analysis}

A549 cells in wells were scraped with sterile scrapers and $5 \times 10^{5}$ cells in $50 \mu \mathrm{L}$ DMEM were incubated with an excess concentration of various mAbs (anti-CD54 (antiICAM-1), anti-CD106 (anti-VCAM-1), anti-E-cadherin, and anti-MHC class I and class II antigens; with X63 used as a negative control) for $30 \mathrm{~min}$ on ice. The cells were washed twice with phosphate-buffered saline (PBS) containing sodium azide and labelled with Silenus antimouse $\mathrm{F}\left(\mathrm{ab}^{\prime}\right)_{2}$ fragment conjugated to FITC (AMRAD, Boronia, 
Australia) diluted 1:100. The cells were incubated for another $30 \mathrm{~min}$ on ice. After two washes with PBS/sodium azide, the cells were analysed by means of FACScan flow cytometry (CellQuest, Los Angeles, CA; Becton Dickinson, LA, CA) using standard settings. Ten thousand cells from each sample were analysed. The mean fluorescence intensity (MFI) on cells in the gated epithelial cell area was measured by means of flow cytometry as a marker of cell surface expression of the above molecules. All data were collected from three separate experiments.

\section{Immunocytostaining}

The reagent kit was purchased from Signet Laboratories Inc. (Dedham, MA, USA). Briefly: 1) all primary antibodies were prepared in blocking reagent (normal serum in buffer, multispecies); 2) the specimens (A549 cells in eightchamber slides) were fixed in $95 \%$ ethanol for $15 \mathrm{~min}$ and washed in tris (hydroxymethyl) amino methane (Tris)-buffered saline (TBS) for $5 \mathrm{~min} ; 3$ ) the specimens were incubated with the correct titres of primary antibody diluted in blocking reagent in a humid incubation tray overnight at $4^{\circ} \mathrm{C}$, and were washed in three changes of TBS, each for 5 min; 4) the endogenous peroxidase activity was blocked in $1 \% \mathrm{H}_{2} \mathrm{O}_{2}$ diluted in absolute ethanol for $10 \mathrm{~min}$ and the specimens were washed in TBS for $5 \mathrm{~min}$; 5) the specimens were incubated in linking reagent (biotinylated antimouse plus antirabbit immunoglobulins in buffer, multispecies) for $30 \mathrm{~min}$ at room temperature and were washed three times in TBS; 6) the specimens were incubated in labelling reagent (ultra streptavidin/peroxidase labelled in buffer) for $30 \mathrm{~min}$ at room temperature and were washed three times in TBS; 7) the specimens were incubated in $3^{\prime} 3^{\prime}$-diaminobenzidine tetrahydrochloride (DAB) solution for $5 \mathrm{~min}$ at room temperature and were washed well in TBS followed by tap water; 8) the slides were stained in Lillie Mayer's haematoxylin for $2 \mathrm{~min}$, differentiated briefly in $0.5 \%$ acid alcohol, blued in aqueous lithium carbonate, dehydrated in ethanol, cleared in xylol and mounted in PIX; and 9) photomicrographs were taken.

\section{Statistical analysis}

Data are presented as mean \pm SEM. Differences in results between groups were examined using one-way analysis of variance. The $p$-values between groups were corrected using Bonferroni's test. Differences were considered to be significant at a $\mathrm{p}$-value of $<0.05$.

\section{Results}

The expression of intercellular adhesion molecule-1 on A549 cells in respiratory syncytial virus infection

ICAM-1 was weakly expressed on normal A549 cells compared with negative control X63 (MFI $36.8 \pm 1.3$ versus $30 \pm 1.6$ ) (fig. 1). At $48 \mathrm{~h}$ of infection, RSV upregulated ICAM-1 expression in a dose-dependent pattern and reached a maximum level at a MOI of 1.0 (MFI 93 \pm 6.1 ) (fig. 1). However, RSV infection at a MOI of 1.0 upregulated ICAM-1 to the maximum level even at $6 \mathrm{~h}$ of infection (MFI 102 \pm 11.9 ), although there was no significant ICAM-1 upregulation after RSV infection at a MOI of

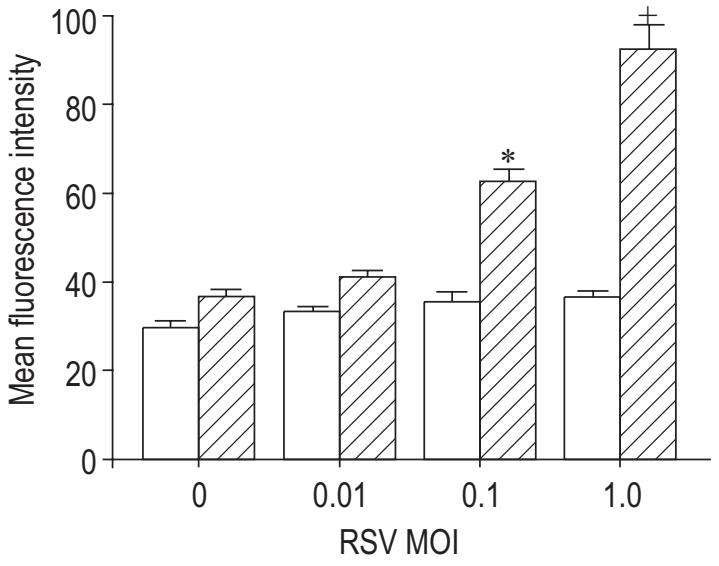

Fig. 1. - Intensity of intercellular adhesion molecule-1 expression on A549 cells infected with respiratory syncytial virus (RSV) at different multiplicities of infection (MOIs) for $48 \mathrm{~h}(\mathbb{Z})$. X63 $(\square)$ was used as negative control. Data are presented as mean $\pm \operatorname{SEM}(n=3)$. *: $\mathrm{p}<0.05$ versus $\mathrm{MOI}$ of 0 group; + : $\mathrm{p}<0.05$ versus $\mathrm{MOI}$ of $0,0.01$ and 0.1 groups.

0.01 and 0.1 for 6 and $24 \mathrm{~h}$. Immunostaining studies showed that ICAM-1 was strongly expressed around or in RSV-induced syncytial cells or giant cells (fig. 2).

The expression of vascular cell adhesion molecule-1 on A549 cells infected with respiratory syncytial virus

VCAM-1 is also weakly expressed on normal A549 cells compared with X63 (MFI 45 \pm 1.3 versus 30 \pm 1.6 , $\mathrm{p}>0.05$ ) (fig. 3). At $48 \mathrm{~h}$ of RSV infection, VCAM-1 expression was upregulated in a dose-dependent manner and was at its highest with RSV at a MOI of 1.0 (MFI 73 \pm 4 ) (fig. 3). However, RSV infection at a MOI of 1.0 could upregulate VCAM-1 to the maximum level even at $6 \mathrm{~h}$ of infection (MFI $83 \pm 2.9$ ), although there was no significant VCAM-1 upregulation after RSV infection at MOIs of 0.01 and 0.1 for either 6 or $24 \mathrm{~h}$. Similarly to ICAM-1, VCAM-1 was also strongly upregulated around or in RSV-induced giant cells (fig. 2).

The expression of major histocompatibility complex class I and II antigens on A549 cells in respiratory syncytial virus infection

Class I antigen is constitutively expressed on normal A549 cells compared with X63 (MFI $405 \pm 40$ versus $30 \pm 1.6$ ), and RSV infection for $48 \mathrm{~h}$ could upregulate class I expression on these cells in a dose-dependent pattern and reached a maximum level with RSV at a MOI of 1.0 (MFI $918 \pm 43$ ) (fig. 4). There is effectively a doubling of class I antigen expression after RSV infection. However, there was no significant class I antigen upregulation at $6 \mathrm{~h}$ of RSV infection at a MOI of 1.0 . At $24 \mathrm{~h}$ of RSV infection with a MOI of 1.0, class I antigen expression reached its peak $(916 \pm 39)$ and there was no more upregulation at 48 $\mathrm{h}$ of infection.

Class II antigen was weakly expressed on normal A549 cells compared with X63 (MFI $36 \pm 1.3$ versus $30 \pm 1.6$ ), and RSV infection for $48 \mathrm{~h}$ at a MOI of 1.0 could upregulate class II antigen expression slightly compared with control cells and RSV infection at a MOI of 0.01 (MFI 45.4 \pm 1.5 versus $36 \pm 1.3,39 \pm 0.7, \mathrm{p}<0.05$, respectively) (fig. 5). Both 


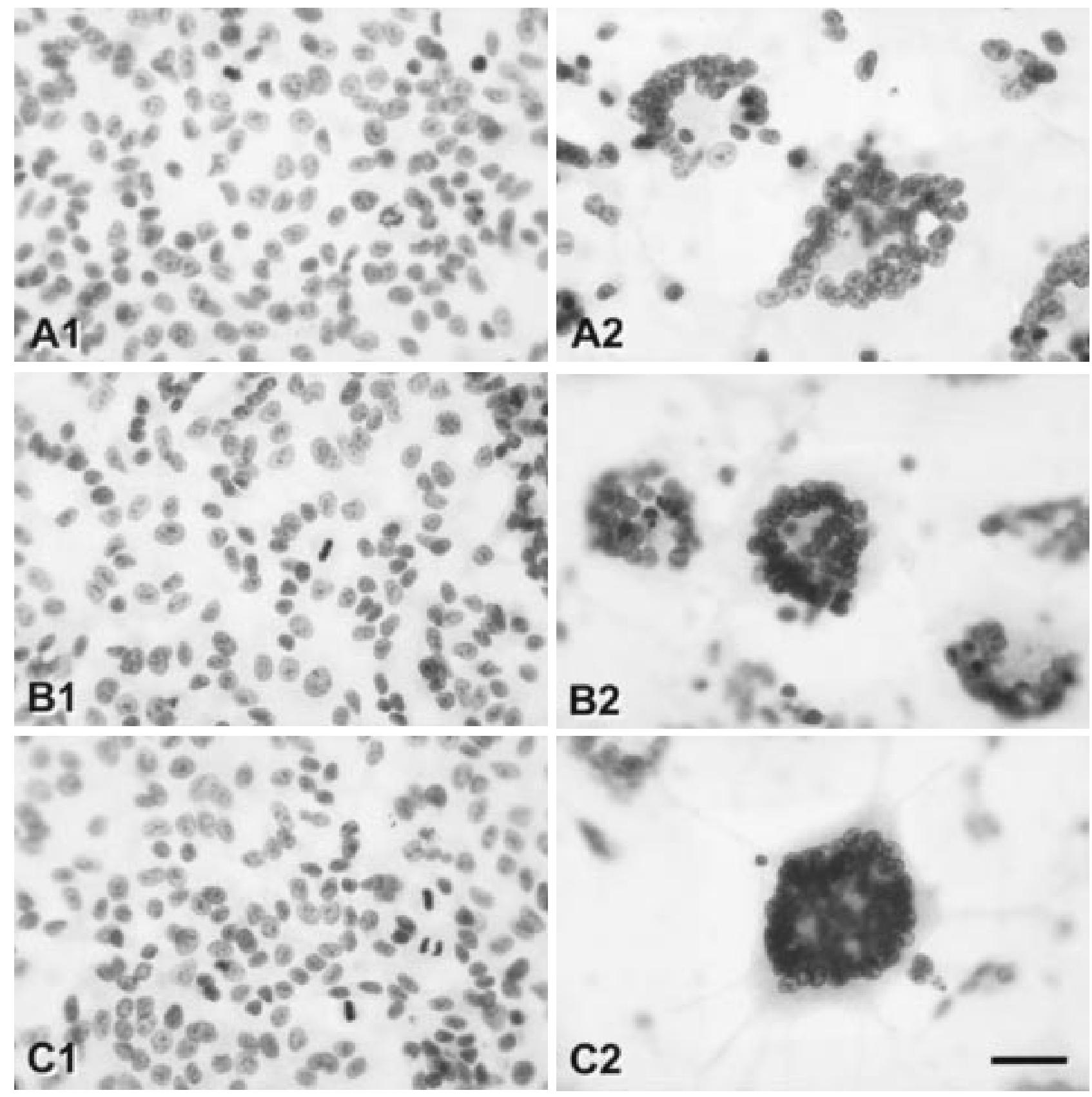

Fig. 2. - Respiratory syncytial virus (RSV)-induced syncytial (giant) cells and upregulation of adhesion molecules (intercellular adhesion molecule-1 (ICAM-1), vascular cell adhesion molecule-1 (VCAM-1) and E-cadherin) on A549 cells. A549 cell monolayers were infected with RSV at a multiplicity of infection of 1.0 for $48 \mathrm{~h}$ (A2, B2 and C2), with noninfected A549 cell monolayers (A1, B1 and C1) as controls: A1, A2 negative controls; B1, B2 ICAM-1 expression; and C1, C2 VCAM-1 expression. (Internal scale bar=20 $\mu \mathrm{m}$.)

MHC class I and II antigens were mainly upregulated around or in the giant cells (fig. 6).

The expression of E-cadherin on A549 cells infected with respiratory syncytial virus

E-cadherin expressed on A549 cell cultures was downregulated with the extension of culture time in both control and infection groups. However, at $48 \mathrm{~h}$ of infection, RSV could upregulate E-cadherin expression even at a MOI of 0.01 (MFI $144 \pm 8.6$ versus $100 \pm 9.0, p<0.05$ ). Immunos- taining supports the view that E-cadherin is mainly upregulated on the RSV-induced giant cells (fig. 2).

\section{Discussion}

The present data show that RSV infection upregulates the expression of ICAM-1, VCAM-1 and MHC class I and II antigens on cultured A549 cells, and could also affect the expression of E-cadherin on these cells. These findings may not necessarily be highly specific for RSV, as RSVi as an additional control was not used [3]. 


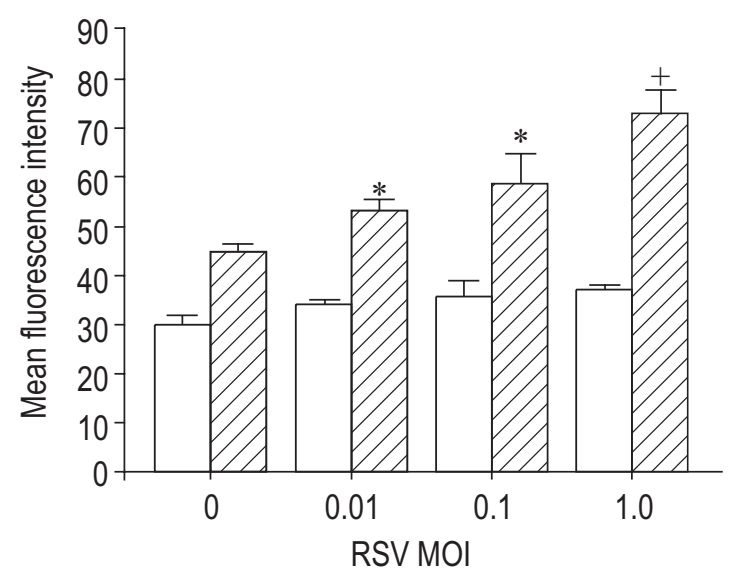

Fig. 3. - Intensity of vascular cell adhesion molecule-1 expression on A549 cells infected with respiratory syncytial virus (RSV) at different multiplicities of infection (MOIs) for $48 \mathrm{~h}(\mathbb{Z})$. X63 ( $\square$ ) was used as negative control. Data are presented as mean $\pm \operatorname{SEM}(\mathrm{n}=3)$. *: $\mathrm{p}<0.05$ versus $\mathrm{MOI}$ of 0 group. $+: \mathrm{p}<0.05$ versus $\mathrm{MOI}$ of 0.01 and 0.1 groups.

ICAM-1 is expressed on a variety of cells including endothelial cells, epithelial cells, fibroblasts and leukocytes [15]. Endothelial/epithelial cell ICAM-1 participates in the migration of leukocytes out of the blood in response to airway inflammation [22]. Epithelial ICAM-1 is also partially responsible for the enhanced neutrophil adhesion to cultured A549 cells in RSV infection and ICAM-1 is the only known ligand expressed on A549 cells for neutrophil CD18 [5]. The upregulation of ICAM-1 on cultured respiratory epithelial cells in RSV infection could help explain the high percentage of neutrophils in both upper and lower airway washings in infants with RSV bronchiolitis [23], and the increased neutrophil adhesion to A549 cells in RSV infection in vitro [3,5]. The present data show that RSV-induced ICAM-1 expression is timeand dose-dependent, and that high-dose RSV could induce ICAM-1 expression to the maximum level at an early stage. These findings support the results of a previous neutrophil/epithelial adhesion and neutrophil damage study, demonstrating that RSV infection increases neutro-

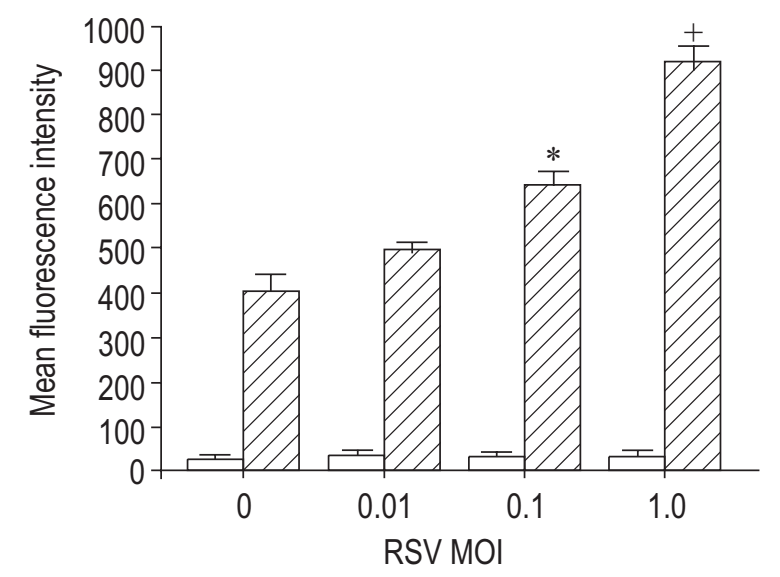

Fig. 4. - Intensity of class I antigen expression on A549 cells infected with respiratory syncytial virus (RSV) at different multiplicities of infection (MOIs) for $48 \mathrm{~h}(\mathbb{C})$. X63 ( $\square$ ) was used as negative control. Data are presented as mean $\pm \operatorname{SEM}(\mathrm{n}=3){ }^{*}: \mathrm{p}<0.05$ versus MOI of 0 group. $+: \mathrm{p}<0.05$ versus $\mathrm{MOI}$ of $0,0.01$ and 0.1 groups.

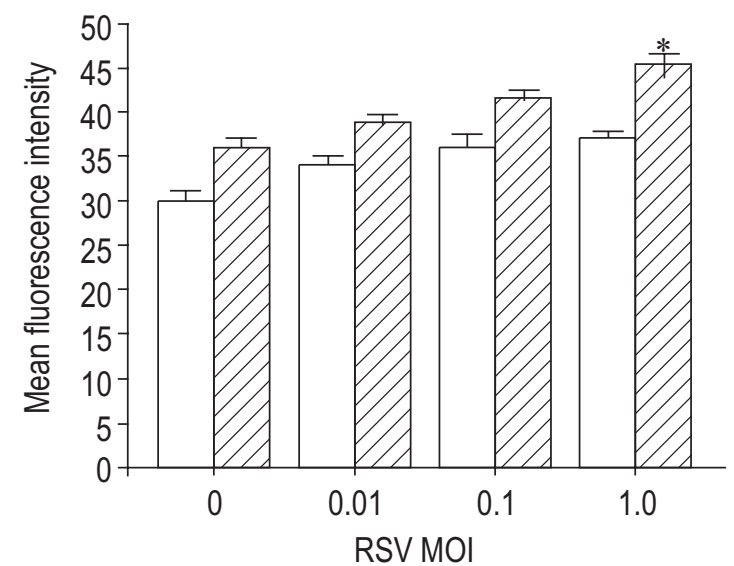

Fig. 5. - Intensity of class II antigen expression on A549 cells infected with respiratory syncytial virus (RSV) at different multiplicities of infection (MOIs) for $48 \mathrm{~h}(\mathbb{Z})$. X63 ( $\square$ ) was used as negative control. Data were presented as mean $\pm \operatorname{SEM}(\mathrm{n}=3)$. *: $\mathrm{p}<0.05$ versus $\mathrm{MOI}$ of 0 group and X63 with a MOI of 1.0 groups.

phil adhesion to epithelial cells in a time- and dosedependent pattern, RSV infection alone can damage and detach epithelial cells to a limited extent, and neutrophils can significantly augment the RSV-induced epithelial damage and detachment [3]. The upregulation of CD18 and CD11b on neutrophils in RSV infection may also contribute to the increased neutrophil/epithelial adhesion and neutrophil-induced epithelial damage [24].

There are several possible mechanisms of ICAM-1 upregulation on respiratory epithelial cells in RSV infection. It has been reported that RSV induces the synthesis of IL- $1 \alpha$, IL- $1 \beta$, and TNF- $\alpha$, and that the enhanced ICAM-1 expression in RSV-infected epithelial cells is mediated primarily by IL-1 $\alpha$ [25]. Another study showed that the upregulation of ICAM-1 on lung epithelial cells, after airway instillation of lipopolysaccharide, was mediated through TNF- $\alpha$ and IL-1 [26]. A more recent study indicated a critical role of the activation of transcription factors $\mathrm{NF}-\kappa \mathrm{B}$ and $\mathrm{C} / \mathrm{EBP}$ in RSV-induced ICAM-1 expression by A549 cells [27].

The present finding that RSV-infected A549 cells express VCAM-1 is in contrast to a previous study [5], which showed no upregulation of VCAM-1 on A549 cells after RSV infection. More recently, another report showed that cytokine (TNF- $\alpha$, IL-1 $\beta$ and IL-4) activation can induce the expression of both ICAM-1 and VCAM-1 on BEAS2B epithelial cells [16]. The inability of STARK et al. [5] to detect the induction of VCAM-1 on A549 cells by RSV may be due to their use of an enzyme immunoassay. The present study employed DAB as a substrate and investigated the reaction by means of microscopy. Furthermore, the intensity VCAM-1 expression was detected and quantified by flow cytometric analysis, which is more sensitive than immunohistochemical techniques [16]. In the study reported here, video image analysis for quantifying epithelial antigen expression in the cell monolayers was unreliable due to significant epithelial cell detachment from the monolayers. Finally, STARK et al. [5] used A549 cells restricted to passage numbers $82-95$, whereas cells were used before passage 45 in the present study; it has been shown that cells older than passage 50 failed to respond to stimulation [16]. 


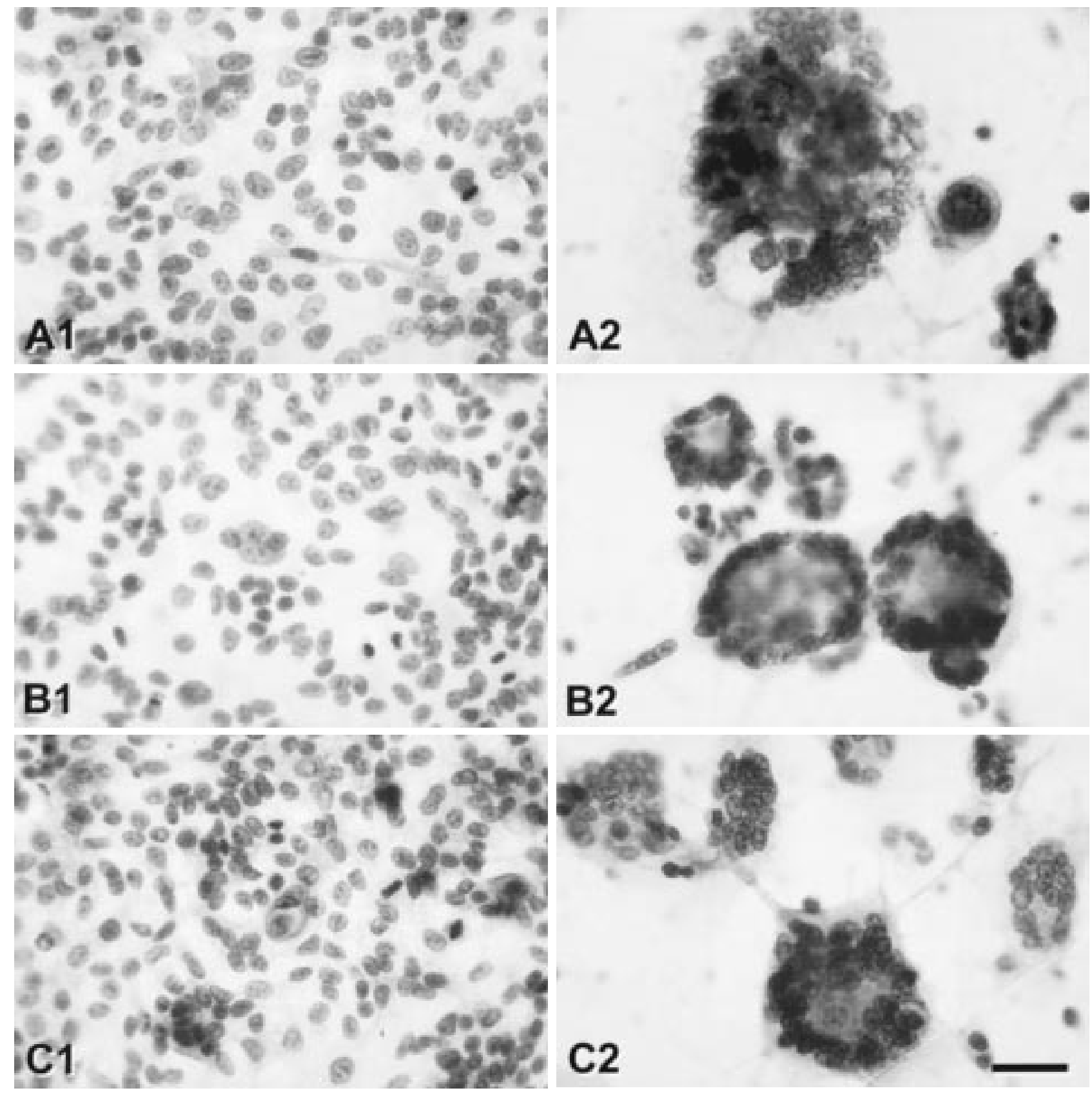

Fig. 6. - Respiratory syncytial virus (RSV)-induced syncytial (giant) cells and upregulation of major histocompatibility complex (MHC) class I and II antigens and E-cadherin on A549 cells. A549 cell monolayers were infected with RSV at multiplicities of infection of 1.0 for $48 \mathrm{~h}$ (A2, B2 and C2), with noninfected A549 cell monolayers (A1, B1 and C1) as controls: A1, A2 MHC class I antigen expression; B1, B2 MHC class II antigen expression; and $\mathrm{C} 1, \mathrm{C} 2 \mathrm{E}$-cadherin expression. (Internal scale bar $=20 \mu \mathrm{m}$.)

The molecular mechanism of RSV-induced VCAM-1 expression on A549 cells is unclear. It has been reported that A549 cells infected with RSV could produce IL- $1 \alpha$, IL-1 $\beta$, and TNF- $\alpha$ [25], and both TNF- $\alpha$ and IL- $1 \beta$ are strong inducers of VCAM-1 expression [16]. The expression of VCAM-1 on respiratory epithelial cells may have important clinical significance. T-lymphocytes and eosinophils express very late activation antigen-4 (VLA-4, CD49d/CD29, $\alpha 4 /$ b1) and can therefore bind to VCAM-1 [28-30]. The role of VLA-4 in the emigration of eosinophils was studied in an in vivo model [31]. Interestingly,
VLA-4 was important for eosinophil rolling after intraperitoneal injection with IL-1 $\beta$. It has been suggested that L-selectin and VLA-4 mediate eosinophil rolling in a sequential manner [31]. More recently, it was also shown that VLA-4/VCAM-1 was involved in the transendothelial migration of lymphocytes in bancroftian filariasis [32]. Most recently, it is reported that both selectin ligands and $\alpha_{4}$ integrins participate in T-lymphocyte recruitment into the airspace during the pulmonary immune response [33]. Taken together, these studies suggest that the upregulation of VCAM-1 on epithelial cells in RSV infection may be 
involved in T-lymphocyte and eosinophil adhesion to epithelial cells and the recruitment of these cells into the airways.

The upregulation of MHC class I antigen expressed on A549 cells in RSV infection confirmed previous observations $[5,34]$. The association of viral antigen with MHC class I antigen in the presence of ICAM-1 supports an interaction with $\mathrm{CD} 8+$ cytotoxic T-cells $[5,34]$. Both MHC class I antigen-restricted cytotoxic T-lymphocytes and lymphoproliferative responses were observed after $\mathrm{RSV}$ infection [36]. In studies of BALB/c mice, it has been shown that CD8 and CD4 T-cells are important for clearing virus infection $[37,38]$. However, cellular immunity also appears to contribute to illness with reinfection by RSV and RSV vaccine-augmented disease [36, 39]. Since CD8 cytotoxic T-cells recognize antigen-laden MHC class I molecules on the target cells, the upregulation of MHC class I antigen on epithelial cells in RSV infection would facilitate the recognition and lysis of the infected epithelial cells by RSV-specific CD8 T-cells. Under these conditions, CD8 T-cells may clear RSV within the epithelial cells and damage or kill the epithelial cells concurrently.

The slight enhancement of MHC class II antigen expression on A549 cells at $48 \mathrm{~h}$ of RSV infection in vitro was an unexpected finding. Another recent study showed that, starting on day 3 of in vivo Sendai virus infection, rat tracheal epithelial cells expressed increasing levels of MHC class II antigen and that this expression was maximal at day 5 and declined rapidly thereafter [40]. As CD4 Tcells recognize antigen-laden MHC class II molecules on the target cells, the expression of MHC class II antigen on A549 cells in RSV infection may enable these cells to have the potential ability to present antigen to CD4 Tcells [41]. This may enable the respiratory epithelium to function as a "nonprofessional" APC, inducing immune inflammatory responses in RSV infection.

The disadvantage of the present in vitro cell model is that it is not possible to keep the cells infected with RSV at a MOI of 1.0 for $>3$ days, because most infected cells will be damaged and detached on the third day of RSV infection and there are limited numbers of cells for flow cytometric and image analysis. Therefore, further study on the expression and role of MHC class II antigen in RSV infection would depend on the establishment of a stable animal model.

The expression of MHC class I and II antigens, ICAM-1 and, VCAM-1, together with the expression of viral antigens on the cell surface [5], may allow the respiratory epithelium to function as a "nonprofessional" APC [18].

E-cadherin is a member of the family of calciumdependent cell adhesion molecules. It is well established that E-cadherin functions as an epithelial adhesion component and is uniformly present at the lateral surfaces of all epithelia independently of their germ layer origin [42, 43]. More recently, it has been reported that E-cadherin is heavily distributed on the basolateral domain of alveolar type II cells [17].

E-cadherin, together with other adhesion molecules, mediate cell/cell or cell/matrix interactions in the lung and play a crucial role in the maintenance of lung tissue architecture [44]. E-cadherin mediates mainly homotypic (to a cell of the same type) epithelial cell-cell adhesion. As E-cadherin is also expressed on the basal side of epithelial cells $[17,45]$, E-cadherin may also be responsible for epithelial adhesion to the basal membrane.

The role of E-cadherin in cancer has been studied widely and it has been confirmed that impaired or reduced Ecadherin expression on tumour cells is associated with dedifferentiation, local invasiveness, lymph node metastasis and unfavourable prognosis [46-49]. However, the expression and clinical significance of E-cadherin on respiratory epithelial cells in RSV infection is unclear. The present immunocytostaining showed that E-cadherin is downregulated on some A549 cells, which may tend to detach later. However the expression of E-cadherin in/ around RSV-induced giant cells is greatly enhanced. Therefore, the downregulation of E-cadherin on A549 cells with increasing culture time may help explain the increasingly enhanced detachment of A549 cell monolayers with an extended culture course [3]. Syncytia induced by RSV infection are usually formed on the second or third day of RSV infection in vitro. The upregulation of Ecadherin on A549 cells at 48 h of RSV infection may be responsible for the formation of syncytial giant cells. Clearly, the roles of E-cadherin in epithelial detachment and in the formation of giant cells in RSV infection requires further study.

The important RSV infection in infants is bronchiolitis. There is now ample evidence that the lower airway inflammation in infants with bronchiolitis is substantially due to host immune factors [10]. The studies described here may help to explain some of the contribution of the respiratory epithelial cell to this inflammation. Clearly in vivo correlates will be necessary to confirm these observations.

In summary, this study suggests that respiratory syncytial virus infection upregulates the expression of intercellular adhesion molecule-1, vascular cell adhesion molecule-1, vascular cell adhesion molecule-1 and major histocompatibility class I and class II antigens on A549 cells. Respiratory syncytial virus infection can also enhance the expression of E-cadherin on A549 cells, especially in or around the giant cells. These changes may play an important role in the pathophysiology of respiratory syncytial virus disease.

\footnotetext{
Acknowledgements. The authors thank M. Lovejoy for assistance in culturing cells and $\mathrm{J}$. Brennan for assistance in immunocytochemistry.
}

\section{References}

1. Papi A. Epithelial ICAM-1 regulation and its role in allergy. Clin Exp Allergy 1997; 27: 721-724.

2. Adler KB, Fischer BM, Wright DT, Cohn LA, Becker S. Interactions between respiratory epithelial cells and cytokines: relationships to lung inflammation. Ann NY Acad Sci 1994; 725: 128-145.

3. Wang S-Z, Xu H, Wraith A, Bowden JJ, Alpers JH, Forsyth KD. Neutrophils induce damage to respiratory epithelial cells infected with respiratory syncytial virus. Eur Respir J 1998; 12: 612-618.

4. Tosi FM, Stark JM, Smith CM, Hamedani A, Gruenert DC, Infeld MD. Induction of ICAM-1 expression on human airway epithelial cells by inflammatory cytokines: 
effects on neutrophil-epithelial cell adhesion. Am J Respir Cell Mol Biol 1992; 7: 214-221.

5. Stark JM, Godding V, Sedgwick JB, Busse WW. Respiratory syncytial virus infection enhances neutrophil and eosinophil adhesion to cultured respiratory epithelial cells: Role of CD18 and intercellular adhesion molecule-1. $J$ Immunol 1996; 156: 4774-4782.

6. Demoly P, Sahla M, Campbell AM, Bousquet J, Crampette L. ICAM-1 expression in upper respiratory mucosa is differentially related to eosinophil and neutrophil inflammation according to the allergic status. Clin Exp Allergy 1998; 28: 731-738.

7. Noah TL, Becker S. Respiratory syncytial virus-induced cytokine production by a human bronchial epithelial cell line. Am J Physiol 1993; 265: L472-L478.

8. Holberg CJ, Wright AL, Martinez FD. Risk factors for respiratory syncytial virus associated lower airway illness in the first year of life. Am J Epidemiol 1991; 133: 11351151.

9. Phelan PD. The epidemiology of acute respiratory infections. In: Robinson MJ, Robertson DM, eds. Practical Paediatrics. 3rd Edn. Melbourne, Churchill Living-stone, 1994; pp. 341.

10. Wang S-Z, Forsyth KD. Asthma and respiratory syncytial virus infection in children: is there a link? Clin Exp Allergy 1998; 28: 927-935.

11. Mastronarde JG, Monick MM, Hunninghake GM. Oxidant tone regulates IL-8 production in epithelium infected with respiratory syncytial virus. Am J Respir Cell Mol Biol 1995; 13: 237-244.

12. Patel J, Faden H, Sharma S, Ogra PL. Effect of respiratory syncytial virus on adherence, colonization and immunity of non-typable Haemophilus influenzae: implications for otitis media. Internat J Pediatr Otorhinolaryngol 1992; 23: $15-23$

13. Saito T, Deskin RW, Casola A, et al. Respiratory syncytial virus induces selective production of chemokine RANTES by upper airway epithelial cells. J Infect Dis 1997; 175: 497-504.

14. Olszewska-Pazdrak B, Casola A, Saito T, et al. Cellspecific expression of RANTES, MCP-1, and MIP- $1 \alpha$ by lower airway epithelial cells and eosinophils infected with respiratory syncytial virus. $J$ Virol 1998; 72: 4756-4764.

15. Bloemen PGM, Henricks PAJ, Nijkamp FP. Cell adhesion molecules and asthma. Clin Exp Allergy 1997; 27: 128141.

16. Atsuta J, Sterbinsky SA, Plitt J, Schwiebert LM, Bochner BS, Schleimer RP. Phenotyping and cytokine regulation of the BEAS-2B human bronchial epithelial cell: demonstration of inducible expression of the adhesion molecules VCAM-1 and ICAM-1. Am J Respir Cell Mol Biol 1997; 17: 571-582.

17. Kasper M, Behrens J, Schuh D, Müller M. Distribution of E-cadherin and Ep-CAM in the human lung during development and after injury. Histochemistry 1995; 103: 281-286.

18. Nickoloff BJ, Turka LA. Immunological functions of non-professional antigen-presenting cells: new insights from studies of T-cell interactions with keratinocytes. Immunol Today 1994; 15: 464-469.

19. Rothlein R, Czajkowski M, O'Neill MM, Marlin SD, Mainolfi E, Merluzzi VJ. Induction of intercellular adhesion molecule-1 on primary and continuous cell lines by pro-inflammatory cytokines. J Immunol 1988; 141: $1665-1669$.

20. Forsyth KD, Talbot V. Assessment of endothelial immunophenotype-limitation of flow cytometric analysis. J Immunol Methods 1991; 144: 93-99.

21. Reed LJ, Muench H. A simple method of estimating fifty per cent endpoints. Am J Hyg 1938; 27: 493-497.

22. Nario RC, Hubbard AK. Localization of intercellular adhesion molecule-1 (ICAM-1) in the lung of silicaexposed mice. Environ Health Perspect 1997; 105 (Suppl. 5): 1183-1190.

23. Everard ML, Awarbrick A, Wrightham M, et al. Analysis of cells obtained by bronchial lavage of infants with respiratory syncytial virus infection. Arch Dis Child 1994; 71: 428-432.

24. Wang S-Z, Smith PK, Lovejoy M, Bowden JJ, Alpers JH, Forsyth KD. Shedding of L-selectin and PECAM-1 and upregulation of Mac-1 and ICAM-1 on neutrophils in RSV bronchiolitis. Am J Physiol 1998; 275: L983-L989.

25. Patel JA, Kunimoto M, Sim TC, et al. Interleukin-1a mediates the enhanced expression of intercellular adhesion molecule-1 in pulmonary epithelial cells infected with respiratory syncytial virus. Am J Respir Cell Mol Biol 1995; 13: 602-609.

26. Beck-Schimmer B, Schimmer RC, Warner RL, et al. Expression of lung vascular and airway ICAM-1 after exposure to bacterial lipopolysaccharide. Am J Respir Cell Mol Biol 1997; 17: 344-352.

27. Chini BA, Fiedler MA, Milligan L, Hopkins T, Stark JM. Essential roles of NF- $\kappa \mathrm{B}$ and $\mathrm{C} / \mathrm{EBP}$ in the regulation of intercellular adhesion molecule-1 after respiratory syncytial virus infection of human respiratory epithelial cell cultures. J Virol 1998; 72: 1623-1626.

28. Shimizu Y, Newman W, Gopal TV, et al. Four molecular pathways of the T-cell adhesion to endothelial cells: roles of LFA-1, VCAM-1, and ELAM-1 and changes in pathway hierarchy under different activation conditions. $J$ Cell Biol 1991; 113: 1203-1212.

29. Oppenheimer-Marks N, Davis LS, Bogue TD, Ramberg J, Lipsky PE. Differential utilization of ICAM-1 and VCAM1 during the adhesion and transendothelial migration of human lymphocytes. J Immunol 1991; 147: 2913-2921.

30. Walsh GM, Mermod J-J, Hartnell A, Kay AB, Wardlaw AJ. Human eosinophil, but not neutrophil, adherence to IL-1-stimulated human umbilical vascular endothelial cells is $\alpha 4 / \beta 1$ (very late antigen-4) dependent. J Immunol 1991 ; 146: 3419-3423.

31. Sriramarao P, Von Andrian UH, Butcher EC, Bourdon MA, Broide DH. L-selectin and very late antigen-4 integrin promote eosinophil rolling at physiological rates in vivo. J Immunol 1994; 53: 4238-4246.

32. Freeman DO, Parker-Cook S, Maia e Silva MC, Braga C, Maciel A. Very late antigen-4/vascular cell adhesion molecule-1 (VLA-4/VCAM-1) pathway is involved in the transendothelial migration of lymphocytes in bancroftian filariasis. J Immunol 1996; 156: 2901-2908.

33. Wolber FM, Curtis JL, Maly P, et al. Endothelial selectins and $\alpha 4$ integrins regulate independent pathways of Tlymphocyte recruitment in the pulmonary immune response. J Immunol 1998; 161: 4396-4403.

34. Garofalo R, Mei F, Espejo R, et al. Respiratory syncytial virus-infection of human respiratory epithelial-cells upregulates class I MHC expression through the induction of IFN- $\beta$ and IL-1- $\alpha$. J Immunol 1996; 157: 25062513.

35. Springer T. Adhesion receptors of the immune system. Nature 1990; 346: 425-434.

36. Anderson LJ, Heilman CA. Protective and disease-enhancing immune responses to respiratory syncytial virus. J Infect Dis 1995; 171: 1-7. 
37. Graham BS, Bunton LA, Wright PF, Karzon DT. Role of $\mathrm{T}$ lymphocyte subsets in the pathogenesis of primary infection and rechallenge with respiratory syncytial virus in mice. $J$ Clin Invest 1991; 88: 1026-1033.

38. Graham BS, Bunton LA, Roland J, Wright PF, Karzon DT. Respiratory syncytial virus infection in anti-treated mice. J Virol 1991; 65: 4936-4942.

39. Connors M, Kulkarni AB, Firestone CY, et al. Pulmonary histopathology induced by respiratory syncytial virus (RSV) challenge of formalin-inactivated RSV-immunized $\mathrm{BALB} / \mathrm{c}$ mice is abrogated by depletion of CD4+ T cells. $J$ Virol 1992; 66: 7444-7451.

40. McWilliam AS, Marsh AM, Holt PG. Inflammatory infiltration of the upper airway epithelium during Sendai virus infection: involvement of epithelial dentritic cells. $J$ Virol 1997; 71: 226-236.

41. Rohn WM, Lee YJ, Benveniste EN. Regulation of class II MHC expression. Crit Rev Immunol 1996; 16: 311-330.

42. Takeichi M. The cadherins: cell-cell adhesion molecules controlling animal morphogenesis. Development 1988; 102: 639-655.

43. Birchmeier W, Weidner KM, Hulsken J, Behrens J. Molecular mechanisms leading to cell junctions (cad- herin) deficiency in invasive carcinomas. Semin Cancer Biol 1993; 4: 231-239.

44. Pilewski JM, Albelda SM. Adhesion molecules in the lung: an overview. Am Rev Respir Dis 1993; 148: S31S37.

45. Pizarro A, Benito N, Navarro P, et al. E-cadherin expression in basal carcinoma. Br J Cancer 1994; 69: 157-162.

46. Behrens J, Mareel MM, Van Roy FM, Birchmeier W. Dissecting tumor cell invasion: epithelial cells acquire invasive properties after the loss of uvomorulin-mediated cell-cell adhesion. J Cell Biol 1989; 108: 2435-2447.

47. Frixen UH, Behrens J, Sachs $\mathrm{M}$, et al. E-cadherinmediated cell-cell adhesion prevents invasiveness of human carcinoma cells. J Cell Biol 1991; 113: 173-185.

48. Siitonen SM, Kononen JT, Helin HJ, Rantala IS, Holli $\mathrm{KA}$, Isola JJ. Reduced E-scadherin expression is associated with invasiveness and unfavorable prognosis in breast cancer. Am J Clin Pathol 1996; 105: 394-402.

49. Sulzer MA, Leers MPG, van Noord JA, Bollen ECM, Theunissen PHMH. Reduced E-cadherin expression is associated with increased lymph node metastasis and unfavorable prognosis in non-small cell lung cancer. $A m J$ Respir Crit Care Med 1998; 157: 1319-1323. 